\title{
Effect of Silicon Carbide (SiC) Nanoparticles on the Spectroscopic Properties and Performance of PMMA/PC Polymer Blend
}

\author{
H. M. Alhusaiki-Alghamdi \\ Department of Physics, Faculty of Science, University of Jeddah, Jeddah, Saudi Arabia \\ Email: halhusiki@kau.edu.sa
}

How to cite this paper: Alhusaiki-Alghamdi, H.M. (2019) Effect of Silicon Carbide (SiC) Nanoparticles on the Spectroscopic Properties and Performance of PMMA/PC Polymer Blend. Journal of Modern Physics, 10, 487-499.

https://doi.org/10.4236/jmp.2019.105034

Received: March 17, 2019

Accepted: April 5, 2019

Published: April 8, 2019

Copyright ( 2019 by author(s) and Scientific Research Publishing Inc. This work is licensed under the Creative Commons Attribution International License (CC BY 4.0).

http://creativecommons.org/licenses/by/4.0/

\begin{abstract}
Films of polymethyl methacrylate (PMMA)/polycarbonate (PC) polymer blend doped silicon carbide $(\mathrm{SiC})$ nanopowder are synthesized by the casting method. The study for the structural, optical and electrical behavior of PMMA/PC blend without and with low contents $(\leq 0.8 \mathrm{wt} \%)$ of $\mathrm{SiC}$ is done. The change of the structure is investigated from X-ray spectra. After the addition of $\mathrm{SiC}$, the intensity of the main X-ray halo peak at $2 \theta=20.26^{\circ}$ of $\mathrm{PMMA} / \mathrm{PC}$ is decreased, attributed to an interaction between PMMA/PC. It's clear that $\mathrm{SiC}$ is causing an increase in the amorphous regions inside the PMMA/PC blend. The peaks related to SiC are not found attributed using a small amount of $\mathrm{SiC}$ with complete dissolution of $\mathrm{SiC}$. The shift of the intensity for IR bands has supported an interaction between all components. The values of the optical band gap from UV-Vis spectra using indirect transition are decreased with the increase of SiC. The values of the electrical conductivity are low at low frequency attributed to the charge accumulation at the electrode which takes place. The conductivity is increased as the increase of frequency due to the mobility of charge carriers. Furthermore, the conductivity is increased with the increase of $\mathrm{SiC}$ contents. The values of $\varepsilon^{\prime}$ and $\varepsilon^{\prime \prime}$ are very high at the lower frequency and they decrease when the frequency is increased attributed to the effect. The plot of both $Z^{\prime}$ and $Z^{\prime \prime}$ shows dramatic decrease with the increase of frequency.
\end{abstract}

\section{Keywords}

PMMA/PC Blend, SiC Nanoparticles, XRD, FT-IR, Electrical Properties

\section{Introduction}

The blend between at least two polymers has given another direction to making 
novel materials [1]. It is a basic and conservative system for altering distinctive properties of the polymers. The blend between the polymers is the technique to upgrade and improve some physical properties of the polymers [2] [3]. The blends between the polymers give a new material. This new material has a good property best than individual polymer. Polycarbonate (PC) is a thermoplastic polymer utilized of advanced applications due to their properties, for example, as strong hydrophobicity, high melt viscosity, the sensitivity of mechanical properties, and softness [4] [5]. To enhance the properties of PC blend, fillers including organic as well as inorganic nanoparticles have additionally been used in a wide range [5] [6].

The blend between polymethyl methacrylate (PMMA) and PC is one of the most profoundly examined polymer pairs and it has received considerable research consideration [7]. This fact is attributed to the transportation of PMMA as a commercial polymer and to PC as an ideal polymer choice in the industry due to its characteristics. A couple of researchers have considered the blend between PC and PMMA to utilize in both industry and research [8]. The greater part of the studies has been centered around the examination of the structure which has been found depending on the method of preparation [9] [10] [11].

Silicon carbide nanostructures have specific properties useful for applications in microelectronics and optoelectronics [12] [13] [14]. Actually, SiC has selected due to their properties as a high hardness, semiconductor processing equipment, etc. These characteristics make $\mathrm{SiC}$ a perfect possibility for high-power electronic devices. A lot of works are represented on $\mathrm{SiC}$ combination since the assembling procedure began. Optically, $\mathrm{SiC}$ shows weak release at room temperature by virtue of its backhanded band hole. $\mathrm{SiC}$ is used in a wide range as utilized as reinforcement in nanocomposites. Silicon carbide nanocomposites have different advantages as far as their performance for use as special structural materials attribute to their excellent properties [15] [16]. This is accepted to be caused by discouraged non-radiative recombination in the confined clusters. SiC nanostructures have a great wonderful property which searches useful for applications in microelectronics and optoelectronics [17].

The aim of this article is to prepare and characterize polymethyl methacrylate (PMMA) and polycarbonate (PC) polymer blend doped with $0.0,0.2,0.4,0.6$ and $0.8 \mathrm{wt} . \%$ of silicon carbide $(\mathrm{SiC})$ nanoparticles. The X-ray diffraction (XRD), Fourier transform infrared (FT-IR) spectroscopy, Ultraviolet-visible (UV-Vis) spectroscopy, and AC conductivity are used to characterize and study the enhancements of the structural, optical and electrical properties of PMMA/PC blend without and with low contents of $\mathrm{SiC}$.

\section{Experimental Details}

\subsection{Materials Used}

Polymethylmethacrylate (PMMA) has $\mathrm{M}_{\mathrm{w}}=1.5 \times 10^{4} \mathrm{G} /$ mole and commercial 
polycarbonate $(\mathrm{PC})$ has $\mathrm{M}_{\mathrm{w}}=2.47 \times 10^{4} \mathrm{G} /$ mole are used as a host material. The MMA and PC are purchased from ACROS Company (New Jersey, USA). The blend samples are synthesis by the solution casting method using chloroform as a common solvent. Silicon carbide $(\mathrm{SiC})$ nanopowder, $<100 \mathrm{~nm}$ particle size is obtained from Sigma Aldrich company.

\subsection{Preparation of the Samples}

The amount of both PMMA and PC are dissolved individually in chloroform using the ratio $70: 30 \mathrm{wt} \%$, respectively. The silicon carbide (SiC) nanopowder is dissolved and suspended in chloroform with a stirrer by an ultrasonic bath for $20 \mathrm{~min}$. Finally, various concentrations of silicon carbide $(0,0.2,0.4,0.6$ and $0.8 \mathrm{wt} \%$ ) is added in the polymer mixture as a dopant and stirred with the sonicator further for another $20 \mathrm{~min}$ to confirm the distribution of $\mathrm{SiC}$ inside the PMMA/PC blend. The final nanocomposite solution is then cast onto a glass plate to get a nanocomposites film with uniform thickness $(150 \mu \mathrm{m})$. The films of PMMA/PC-SiC are left to dry at $50^{\circ} \mathrm{C}$ about $48 \mathrm{~h}$ using a vacuum oven.

\subsection{Characterization}

The X-ray diffraction spectra are measured using a PANalytical X'Pert PROXRD with filtered CuK $\alpha$-radiation $(\lambda=1.54056 \AA)$ at $40 \mathrm{kV}$ acceleration and $10 \mathrm{~mA}$ currents. The FT-IR spectra are recorded on Nicolet iS10, USA spectrometer having a resolution $4 \mathrm{~cm}^{-1}$ in the wavenumber from 4000 to $400 \mathrm{~cm}^{-1}$ to examine their structure. Ultraviolet-visible (UV-vis) absorption spectra of polymer films are recorded using (V-570 UV/VIS/NIR, JASCO) in the wavelength range 195 $1100 \mathrm{~nm}$. The AC electrical studies are done in a frequency range from $10^{-1}$ to $10^{7}$ $\mathrm{Hz}$, using novo-control technologies broadband dielectric spectroscopy. The possible mechanism of the interaction between the components in PMMA/PC-SiC nanocomposites. Firstly, the interaction between the two polymer is occur through the function groups and then the reaction between the polymer blend and $\mathrm{Si}^{+}$after breaking of the carboxyl group.
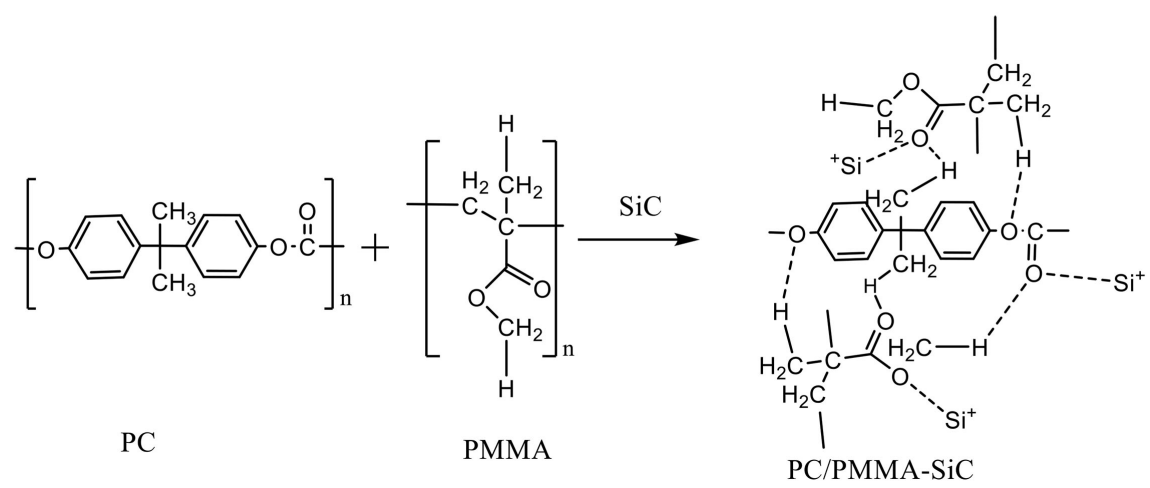

Scheme 1. The possible mechanism of the interaction between the components in PMMA/PC-SiC nanocomposites. 


\section{Results and Discussion}

\subsection{The X-Ray Diffraction Analysis}

The X-ray diffraction is utilized to study the effect for different amounts $(0,0.2$, $0.4,0.6$ and 0.8$)$ of silicon carbide $(\mathrm{SiC})$ on the crystalline structure of pure PMMA/PC. Figure 1 displays the X-ray diffraction for PMMA/PC without and with various concentration of $\mathrm{SiC}$ at $2 \theta=5^{\circ}-75^{\circ}$. The hump (amorphous nature) is observed in the spectra around $2 \theta=16^{\circ}$ is attributed to PMMA. The spectrum of pure PMMA/PC blend depicts the characteristic halo peak observed at $2 \theta=20.26^{\circ}$. After addition of $\mathrm{SiC}$, the intensity of this main peak is decreased and became broader attributed to an interaction between the PMMA/PC and the $\mathrm{SiC}$ causes a decrease in the intermolecular interaction as well as the increase of the amorphous regions between the polymeric chains. The amorphous kind of materials causes an increase of the conductivity [18]. The functional group in the blend implied a decrease in the crystallization indicates that there is a compatibility between the silicon carbide and PMMA/PC in amorphous parts in the PMMA/PC matrix. The spectrum of $\mathrm{SiC}$ as we see inset in Figure 1, did not observe any peaks related to $\mathrm{SiC}$ nanopowder attributed to uses of the small amounts of SiC are under detecting limit and/or good dissolution in amorphous phases of $\mathrm{SiC}$ in PMMA/PC matrices.

\subsection{FT-IR Measurement}

Figure 2 displays the FT-IR spectra of PMMA/PC films blend and PMMA/PC doped different concentrations of $\mathrm{SiC}$ nanoparticles at room temperature from 4000 to $400 \mathrm{~cm}^{-1}$. The characteristic absorption bands of PMMA/PC blend are observed. The principal bands of pure PMMA are assigned as: The band at 2954 $\mathrm{cm}^{-1}$ is assigned to $\mathrm{O}-\mathrm{CH}_{3}$ bending and the bands at 1732 and $1250 \mathrm{~cm}^{-1}$ are assigned to stretching frequency of $\mathrm{C}=\mathrm{O}$. The bands at $1446 \mathrm{~cm}^{-1}$ and at $987 \mathrm{~cm}^{-1}$ are assigned to- $\mathrm{CH}$ and $-\mathrm{CH}_{2}$ bending mode, respectively. Two characteristic bands of PMMA are observed at $1062 \mathrm{~cm}^{-1}$ and at $845 \mathrm{~cm}^{-1}$. The main IR bands of PC is assigned as: The band sat $2991 \mathrm{~cm}^{-1}$ is due to $-\mathrm{CH}$ stretching aromatic ring and at $1770 \mathrm{~cm}^{-1}$ is ascribed to stretching carboxyl group $(\mathrm{C}=\mathrm{O})$. The band at $1501 \mathrm{~cm}^{-1}$ is assigned to $\mathrm{C}=\mathrm{C}$-vibration mode and at $1190 \mathrm{~cm}^{-1}$ is assigned to asymmetric stretching carbonate group (O-C-O). In general, the FT-IR analysis displays the characteristic carboxyl $(\mathrm{C}=\mathrm{O})$ stretching bands of PMMA at 1732 $\mathrm{cm}^{-1}$ and of PC at $1770 \mathrm{~cm}^{-1}$, confirming that PMMA-PC blend has been formed [19] [20] [21].

After the addition of $\mathrm{SiC}$ inside the polymeric matrix of PMMA/PC blend, the intensity of some IR bands is decreased with no recognizable changes in their position occur is in comparison with the spectra of the pure blend. This suggests that the $\mathrm{SiC}$ is homogeneously dispersed inside the polymer blend. Likewise, this decrease happens due to weak physical forces connected between $\mathrm{SiC}$ and PMMA/PC than the chemical forces. The increase of SiC helps to occur the interaction between the PMMA/PC as a host material and the SiC. Then, the in- 
tensity of $\mathrm{C}-\mathrm{O}$, and $\mathrm{C}-\mathrm{O}-\mathrm{C}$ groups is to a great extent limited and results in more disturbance for crystallization and an enhancement for the fraction of amorphous phases as confirmed in X-ray analysis.

\subsection{UV-Vis Measurement}

The UV-Vis absorption spectra of the composites in from 190 to $800 \mathrm{~nm}$ appeared in Figure 3. All the spectra show an appearance of two absorption bands at $241 \mathrm{~nm}$ and at $538 \mathrm{~nm}$ that corresponds to the characteristic bands of conjugated unsaturation and carbonyl chromophores, respectively $\left(\pi \rightarrow \pi^{*}\right.$ transition from unsaturated bonds $(\mathrm{C}=\mathrm{O}$ and/or $\mathrm{C}=\mathrm{C})$. The intensity of the edge decreased as increase $\mathrm{SiC}$ amount, confirming that responses to the reactions between all components. The decrease in the band intensity which related to $\mathrm{C}$ $=\mathrm{O}$ is attributed to the photochemical disruption of $\pi$ bonds, which later causes reduction in the intensity after increase of $\mathrm{SiC}$ concentration due to the bonds between oxygen tom and $\mathrm{Si}^{+}$. The electron in the $\pi$ bond undergoes photo-excitation from ground to higher energy state ( $\pi \rightarrow \pi^{*}$ transition) and cleaves the bond.

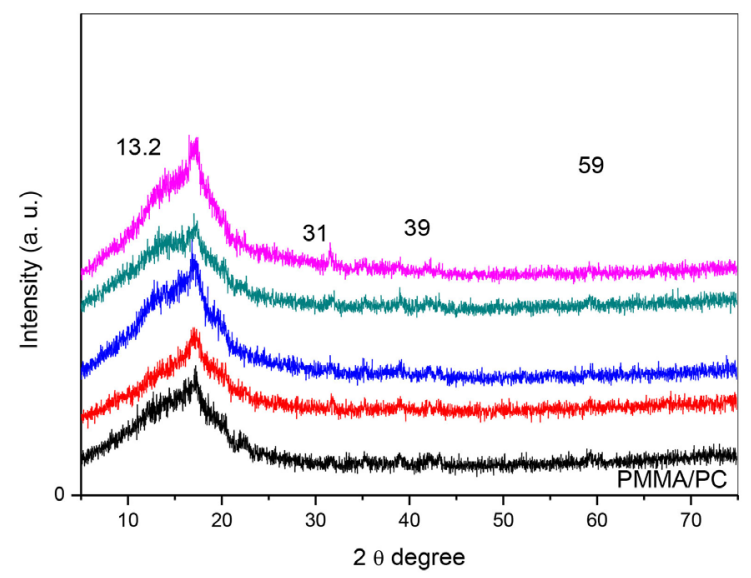

Figure 1. The X-ray diffraction of PMMA/PC doped with SiC nanopowder.

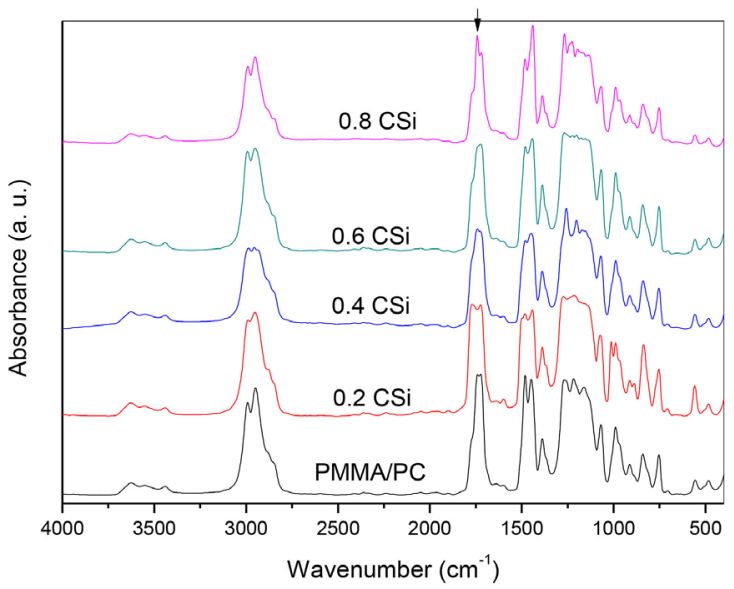

Figure 2. The FT-IR spectra for PMMA/PC doped with SiC nanopowder. 


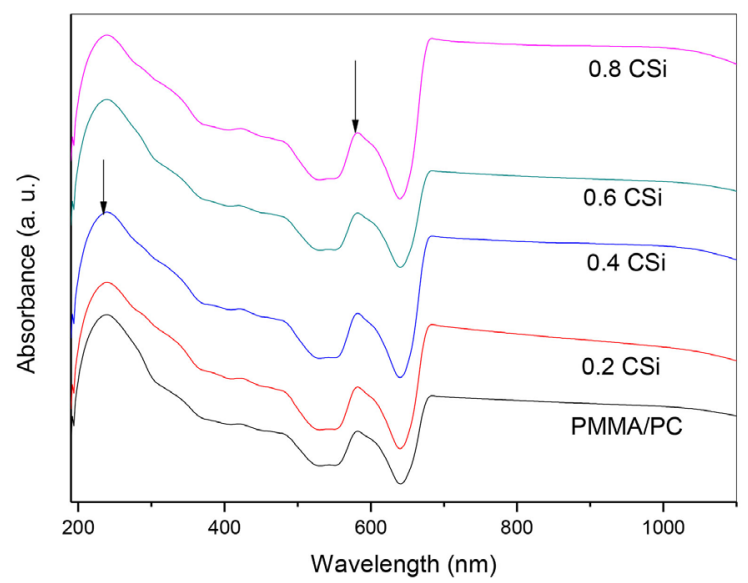

Figure 3. The UV-Vis spectra of PMMA/PC doped with SiC nanopowder.

To study the optical properties of the PMMA/PC-SiC, the optical band gap $\left(E_{g}\right)$ of the prepared nanocomposites is estimated using formula (1) as [22]:

$$
(\alpha h v)^{x}=B\left(h v+E_{g}\right)
$$

where, $\alpha$ is the absorption coefficient, $h v$ is the photon energy ( $h$ is Planck's constant, $\left(\left(v=\frac{c}{\lambda}, c\right.\right.$ is speed of light and $\lambda$ is the wavelength $\left.)\right), B$ is a constant, and $\mathrm{x}=1 / 2,2,3 / 2$ and 3 corresponding to the allowed indirect, allowed direct, forbidden direct and forbidden indirect transitions, respectively. The values of $\alpha(v)$ are determined by the equation:

$$
\alpha(v)=\frac{2.303 A}{d}
$$

where $A$ is absorbance. At the edge, the forbidden direct of $h v$. The band energy $\left(E_{g}\right)$ can be evaluated from the relation between $(\alpha h v)^{3 / 2}$ and of photon energy $(h v)$ as seen in Figure 4. The estimations of $E_{g}$ of the samples are dictated using extrapolating of the straight part of the high energy spectra to the $h v$-axis at zero, and these values are decreased from $3.88 \mathrm{eV}$ to $3.74 \mathrm{eV}$ with the increase of $\mathrm{SiC}$ contents in the PMMA/PC blend. This decrease is expected due to the addition of relatively low energy band gap $\mathrm{SiC}$ into the high energy band gap of PMMA/PC. Also, the decrease of $E_{g}$ attributed to change in the structure of PMMA/PC blend attributed to formation of new bonds between the SiC with blend chains. Another reason for the decrease of $E_{g}$ is the formation of localized state between HOMO and LUMO bands for PMMA/PC, which modified their extended electronic states.

\subsection{The AC Electrical Studies}

\subsubsection{The AC Electrical Conductivity}

The AC electrical conductivity $\sigma(\omega)$ study is performed to incorporate the effect of conduction mechanism and the kinds of charge carriers in the samples. The AC electrical conductivity $\sigma(\omega)$ of the common polymers is calculated using the following empirical equation [23]: 


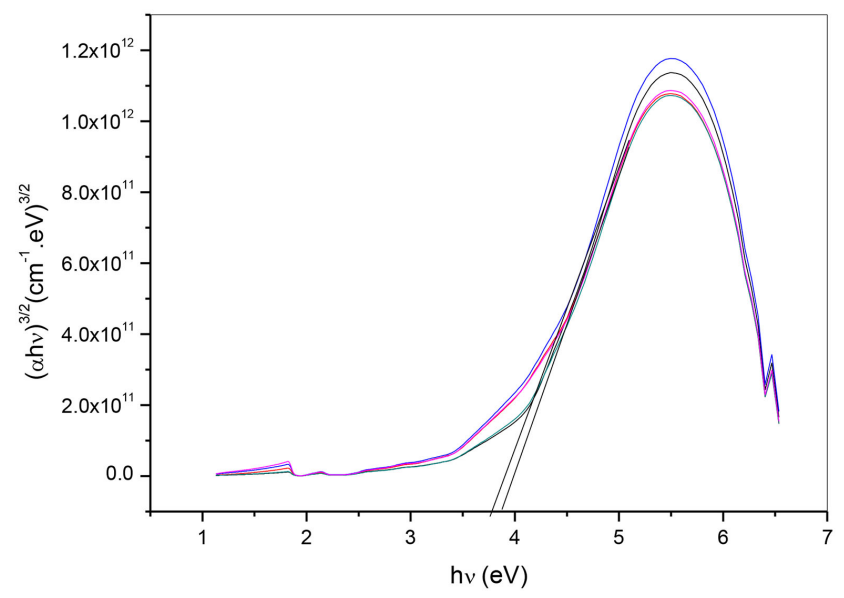

Figure 4. The variation of $(\alpha h v)^{3 / 2}$ depends on the energy $(h v)$ of PMMA/PC doped with SiC nanopowder.

$$
\sigma(\omega)=\omega \varepsilon_{o} \varepsilon^{\prime \prime}
$$

The conductivity of the samples is due to losses of bound charges whereas there should be no such losses under a DC field. Every material will have free charges, and under the applied low frequency, these charges can follow the field and cause conduction current given rise to energy loss. Then the measured AC conductivity is [24]:

$$
\sigma_{m}(\omega)=\sigma_{D C}+\sigma_{A C}(\omega)
$$

where $\sigma_{D C}$ is the $D C$ electrical conductivity and $\sigma_{A C}$ is the true value of $A C$ conductivity. Figure 5 shows the plot between the total electrical conductivity $\sigma(\omega)$ dependence of the frequency $\log (\mathrm{f})$ at room temperature. The values of conductivity are low at low frequency due to the charge accumulation at the electrode interface tacks place which reduces the conductivity. The conductivity is increased as the increase of frequency attributed to the mobility of charge carriers and the hopping of ions from the infinite cluster. As a result, the ion exchange process occurs effectively in the high-frequency region. A relaxation with hopping frequency is observed due to earlier that the conductive species in the samples is effective to the charge carriers. It is observed that the measured electrical conductivity is increased with the increase of $\mathrm{SiC}$ contents.

\subsubsection{The Dielectric Properties}

Figure 6 displays the plot between the angular frequency Log ( $\mathrm{f}$ ) with the dielectric constant $\left(\varepsilon^{\prime}\right)$ and Figure 7 illustrates the relation between plot of dielectric loss $\left(\varepsilon^{\prime \prime}\right)$ against Log f of pure PMMA/PC blend and the PMMA/PC embedded by $0.0,0.2,0.4,0.6$ and $0.8 \mathrm{wt} \%$ of $\mathrm{SiC}$ nanoparticles at room temperature. The Debye equations give the complex permittivity as the following relation [25] [26]:

$$
\varepsilon^{*}=\varepsilon^{\prime}-i \varepsilon^{\prime \prime}=\varepsilon_{\infty}+\frac{\varepsilon_{s}-\varepsilon_{\infty}}{1-j \omega \tau}
$$




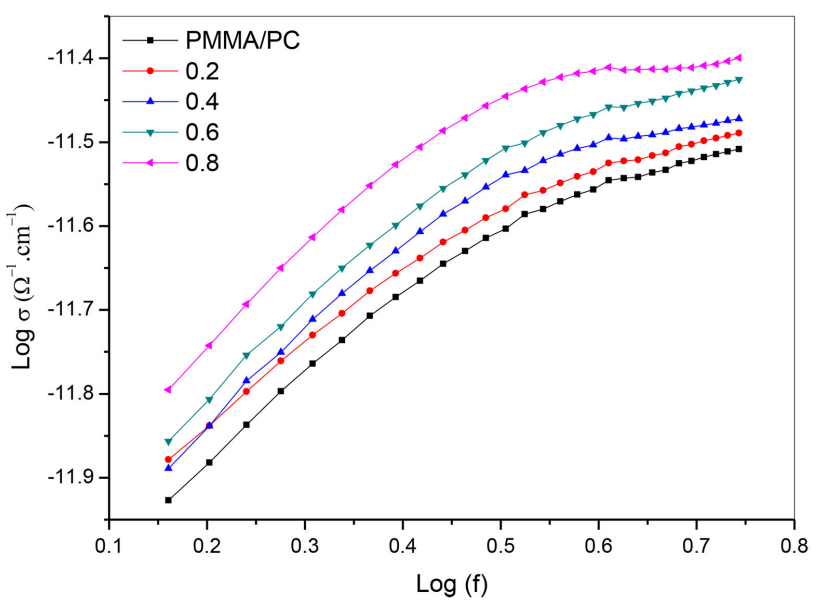

Figure 5. The variation of AC conductivity $(\log \sigma)$ depends on frequency ( $\log$ f) of PMMA/PC doped with SiC nanopowder.

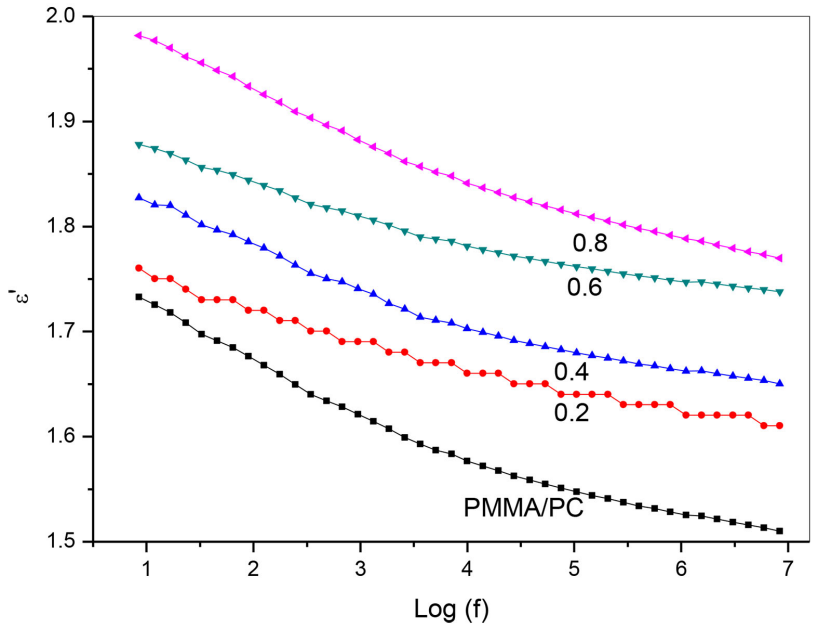

Figure 6. The variation of $\varepsilon^{\prime}$ depends on Log (f) of PMMA/PC doped with $\mathrm{SiC}$ nanopowder.

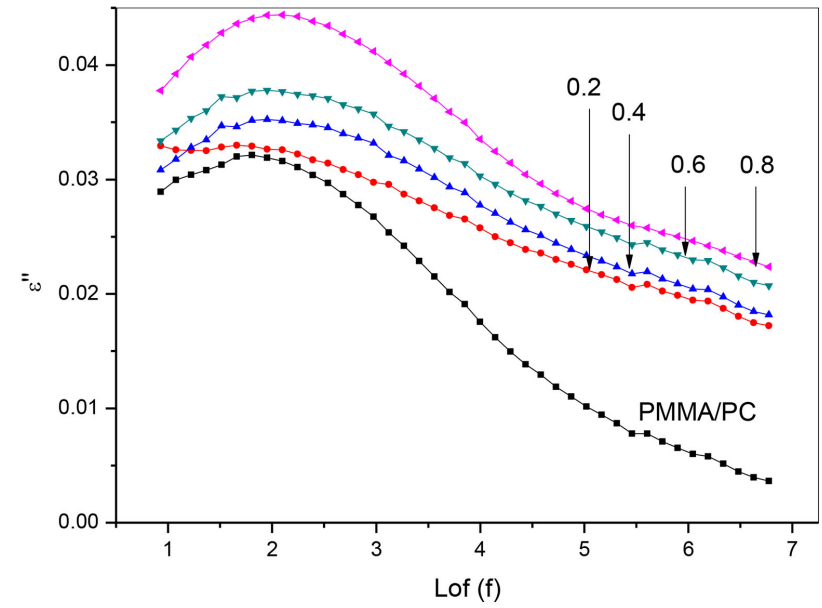

Figure 7. The variation of $\varepsilon^{\prime \prime}$ depends on $\log (\mathrm{f})$ of PMMA/PC doped with $\mathrm{SiC}$ nanopowder. 
where $\varepsilon_{\infty}$ and $\varepsilon_{s}$ are the dielectric constant at high frequency and limiting low frequency of dielectric constant, respectively, is the relaxation time $(\tau=R C)$. The real part $\left(\varepsilon^{\prime}\right)$ and the imaginary part are written as [27]:

$$
\varepsilon^{\prime}=\varepsilon_{\infty}+\frac{\varepsilon_{s}-\varepsilon_{\infty}}{1+\omega^{2} \tau^{2}} \text { and } \varepsilon^{\prime \prime}=\frac{\left(\varepsilon_{s}-\varepsilon_{\infty}\right) \omega \tau}{1+\omega^{2} \tau^{2}}
$$

From the two figures, it is observed that both the behavior of $\left(\varepsilon^{\prime}\right)$ and $\left(\varepsilon^{\prime \prime}\right)$ gradually decrease with the increase of the frequency and it reaches to constant values at higher frequencies. Also, the two estimated values of $\varepsilon^{\prime}$ and $\varepsilon^{\prime \prime}$ are very high at lower frequencies and it decreases with the increase of frequency due to because of polarization effects and because of the dipoles, not start to follow the field variety at higher frequencies. The plots of $\left(\varepsilon^{\prime}\right)$ and $\left(\varepsilon^{\prime \prime}\right)$ as shown in the figures exhibit three regions over the frequency range. In the first region at very low frequencies $\left(\omega \ll \tau \Rightarrow \varepsilon^{\prime}=\varepsilon_{s}\right)$. Then, the dipoles flow the field and the values of $\left(\varepsilon^{\prime}\right)$ and $\left(\varepsilon^{\prime \prime}\right)$ decrease due to dominant contribution of interfacial polarization effect. The second region $\left(\omega \leq \frac{1}{\tau}\right)$, the dipoles begin to lag the field and the relaxation process occurs. At the last region $(\omega \gg \tau)$, the linearity of $\varepsilon^{\prime}$ is tending to approach steady state which can be assigned to the high frequency limiting permittivity $\varepsilon_{\infty}$ values of the polymers. When $\omega \tau \ll$, the estimated values $\left(\varepsilon^{\prime}\right)$ of is equal to $\varepsilon_{s}$. Whereas the plot of $\left(\varepsilon^{\prime \prime}\right)$ has a little decrease it becomes very low. After adding silica nanoparticles to PMMA/PC blend, the frequency is increased due to the dipole will no longer be able to rotate sufficiently rapidly and the oscillation being to be lag those of the applied field. As frequency increased, the dipole will be completely unable to follow the field and the orientation stopped and the value of $\varepsilon^{\prime}$ is decreased and approach to stable due to interfacial polarization. The decrease of $\varepsilon^{\prime \prime}$ with increases of the frequency may be attributed to the origin of $\varepsilon^{\prime \prime}$ is the conduction losses.

\subsubsection{Complex Impedance Study}

The collective plot of complex impedance $Z^{*}$ as a function of frequency can be applied to identify whether the long-range or short-range movement of charge carriers is dominant in the relaxation process. To Interpret the dielectric spectra, different formalism such as complex impedance $Z^{*}$ has been explored. The complex impedance can be evaluated from the following relation [28]:

$$
Z^{*}=Z^{\prime}+i Z^{\prime \prime}
$$

where $Z^{\prime}$ and $Z^{\prime \prime}$ are the real and imaginary part of the complex impedance, which described as [29]:

$$
Z^{\prime}=\frac{R}{1+\omega^{2} \tau^{2}} \text { and } Z^{\prime \prime}=\frac{\omega \tau}{1+\omega^{2} \tau^{2}}
$$

Figure 8 displays the plot between the frequency Log (f) with the real complex impedance $\left(Z^{\prime}\right)$ and Figure 9 illustrates the relationship between the plot of imaginary part of the complex impedance $\left(Z^{\prime \prime}\right)$ against Log fof pure PMMA/PC 
blend and the PMMA/PC embedded of SiC. As we see in the two figures, the behavior of both $Z^{\prime}$ and $Z^{\prime \prime}$ is gradually decreased with the increase of frequency. This behavior is a general trend of dielectrics materials as a polymer that can be understood by polarization which created related to the ionic exchange of the number of ions by locally displacing in the applied field direction. At lowest frequency, there is a charge accumulation at the interface causing contributions for various interfacial polarizations are watched. The discussion of this behavior is that at a certain point, the space charges can't support and comply with the outside field which causes a decrease in the polarization and there is no charge accumulation at the interface. At low frequencies, the real and imaginary part of the complex impedance depends to the presence of ion center type of polarization in the films and to the interfacial polarization. The complex impedance is high at the low frequency that might be because of space charge polarization. It is because obstructing of charge carriers at the electrodes due to confinement to their movement at the interface. The plots further show a decrease in impedance with the increase in silica content.

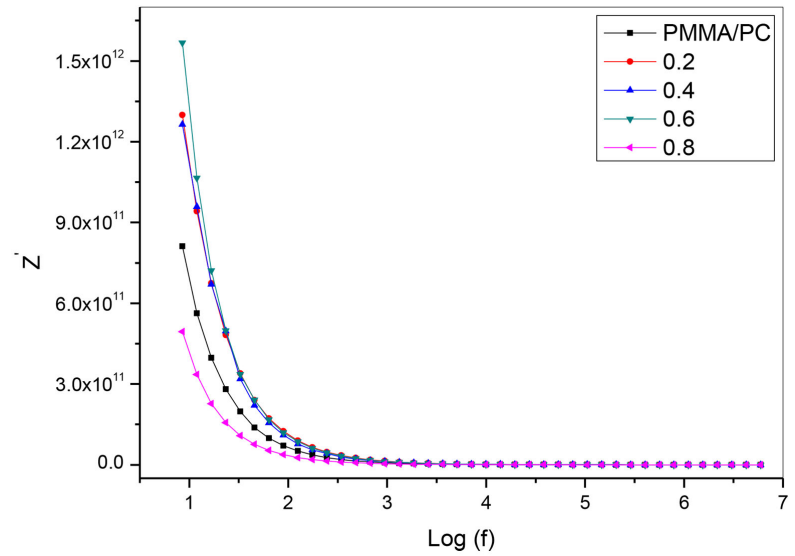

Figure 8. The variation of $Z^{\prime}$ depends on $\log (\mathrm{f})$ of PMMA/PC doped with $\mathrm{SiC}$ nanopowder.

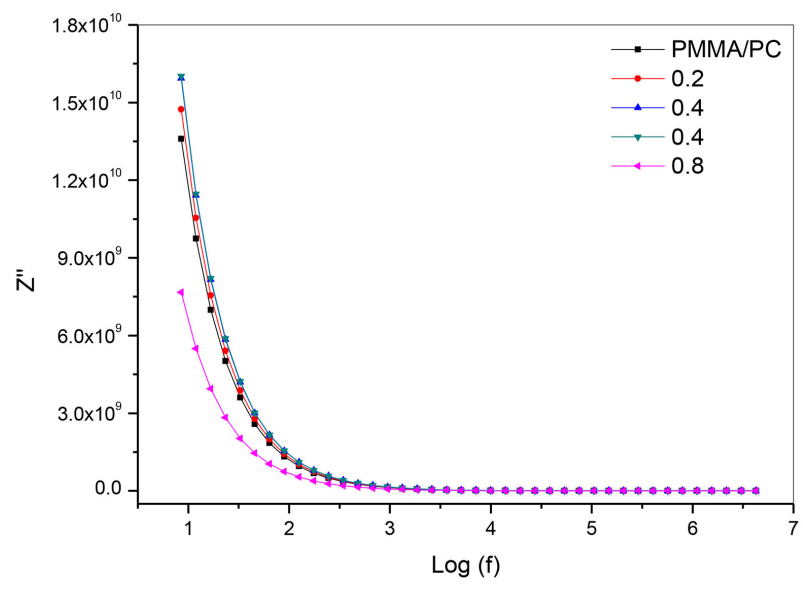

Figure 9. The variation of $Z^{\prime \prime}$ depends on $\log (\mathrm{f})$ of PMMA/PC doped with $\mathrm{SiC}$ nanopowder. 


\section{Conclusion}

Composite samples based on PMMA/PC blend doped silicon carbide (SiC) nanoparticles are prepared and investigated. The structure of the composites is studied using X-ray, FT-IR and UV-Vis spectroscopy. The intensity of the main $\mathrm{X}$-ray peak is decreased according to an interaction between PMMA/PC and SiC causing an increase in the amorphous regions. The main characteristic of X-ray peaks which assigned to $\mathrm{SiC}$ is not founded in all spectra attributed to use a small amount ( $\leq 0.8 \mathrm{wt} \%$ ) of $\mathrm{SiC}$ or due to complete dissolution of $\mathrm{SiC}$ inside the polymeric matrices. The shift of intensity in IR band suggested an interaction between PMMA/PC and SiC. The values of the optical band gap from UV-Vis spectra are decreased by increasing $\mathrm{SiC}$ due to charge transfer. The AC conductivity is low at low frequency due to the charge accumulation at the electrode interface that takes place, which reduces the conductivity. The conductivity is increased as the increase of frequency attributed to the mobility of charge carriers and the hopping of ions from the infinite cluster. Also, the conductivity is increased with the increase of $\mathrm{SiC}$ contents. The values of $\varepsilon^{\prime}$ and $\varepsilon^{\prime \prime}$ are very high at lower frequencies and it decreases with the increase of frequency because of polarization effects and because of the dipoles, not start to follow the field variety at higher frequencies. The values of both $Z^{\prime}$ and $Z^{\prime \prime}$ are gradually decreased with the increase of frequency. At lowest frequency, there is a charge accumulation at the interface causing contributions for various interfacial polarizations are watched. The real and imaginary parts of the complex impedance are decreased at low frequency depends to the presence of ion center type of polarization in the films and to the interfacial polarization. The complex impedance is high at the low frequency because of space charge polarization. The plots further show a decrease in impedance with the increase in silica content.

\section{Conflicts of Interest}

The authors declare no conflicts of interest regarding the publication of this paper.

\section{References}

[1] Rajeh, A., Morsi, M.A. and Elashmawi, I.S. (2019) Vacuum, 159, 430-440. https://doi.org/10.1016/j.vacuum.2018.10.066

[2] Pud, A., Ogurtsov, N., Korzhenko, A. and Shapoval, G. (2003) Progress in Polymer Science, 28, 1701-1753. https://doi.org/10.1016/j.progpolymsci.2003.08.001

[3] Zivanovic, S., Li, J., Davidson, P.M. and Kit, K. (2007) Biomacromolecules, 8, 1505-1510. https://doi.org/10.1021/bm061140p

[4] Malik, T.M., Carreau, P.J. and Chapleau, N. (1989) Polymer Engineering \& Science, 29, 600-608. https://doi.org/10.1002/pen.760290906

[5] Schauries, D., Mota-Santiago, P., Gilbert, E.P., Kirby, N., Trautmanne, C. and Kluth, P. (2018) European Polymer Journal, 108, 406-411.

https://doi.org/10.1016/j.eurpolymj.2018.09.025 
[6] Li, Y., Pötschke, P., Pionteck, J. and Voit, B. (2018) European Polymer Journal, 108, 461-471. https://doi.org/10.1016/j.eurpolymj.2018.09.027

[7] Siddiqui, N., Bhardwaj, A., Hada, R., Yadav, V.S. and Goyal, D. (2018) Vacuum, 153, 6-11. https://doi.org/10.1016/j.vacuum.2018.03.036

[8] Ray, S.S. and Bousmina, M. (2005) Macromolecular Rapid Communications, 26, 450-455. https://doi.org/10.1002/marc.200400586

[9] Nishimoto, M., Keskkula, H. and Pault, D.R. (1991) Polymer, 32, 727.

[10] Montaudo, G., Puglisi, C. and Samperi, F. (1998) Journal of Polymer Science Part A: Polymer Chemistry, 36, 1873-1884.

https://doi.org/10.1002/(SICI)1099-0518(199808)36:11<1873::AID-POLA22>3.0.C O;2-A

[11] Penco, M., Sartore, L., Sciucca, S.D., Landro, L. D. and D'Amore, A. (2007) Macromolecular Symposia, 247, 252-259. https://doi.org/10.1002/masy.200750129

[12] Hu, Z., Liao, X., Diao, H., Kong, G., Zeng, X. and Xu, Y. (2004) Journal of Crystal Growth, 264, 7-12. https://doi.org/10.1016/j.jcrysgro.2003.12.013

[13] Jin, L., Zhang, K., Xu, T., Zeng, T. and Cheng, S. (2018) Ceramics Internship, 44, 20992-20999. https://doi.org/10.1016/j.ceramint.2018.08.134

[14] Luo, Y., Zheng, S., Ma, S., Liu, C. and Wang, X. (2018) Journal of the European Ceramic Society, 38, 5282-5293. https://doi.org/10.1016/j.jeurceramsoc.2018.08.022

[15] Wang, H., Feng, Q., Wang, Z., Zhou, H., Kan, Y., Hu, J. and Dong, S. (2017) Corrosion Science, 124, 131-137. https://doi.org/10.1016/j.corsci.2017.05.016

[16] Chen, J., Jiang, M., Lin, W., Ding, L. and Xin, L. (2018) Journal of Materials Science, 53, 3289-3295. https://doi.org/10.1007/s10853-017-1815-X

[17] Xie, Y., Yang, J., Chen, Y., Liu, X., Zhao, H., Yao, Y. and Cao, H. (2018) Catalysis Today, 315, 223-229. https://doi.org/10.1016/j.cattod.2018.01.013

[18] Elashmawi, I.S., Alatawi, N.S. and Elsayed, N.H. (2017) Results in Physics, 7, 636-640. https://doi.org/10.1016/j.rinp.2017.01.022

[19] Duan, G., Zhang, C., Li, A., Yang, X., Lu, L. and Wang, X. (2008) Nanoscale Research Letters, 3, 118. https://doi.org/10.1007/s11671-008-9123-7

[20] Ghorbel, E., Hadriche, I., Casalino, G. and Masmoudi, N. (2014) Materials, 7, 375-398. https://doi.org/10.3390/ma7010375

[21] Parshin, A.M., Gunyakov, V.A., Zyryanov, V.Y. and Shabanov, V.F. (2013) International Journal of Molecular Sciences, 14, 16303-16320. https://doi.org/10.3390/ijms140816303

[22] Hashim, A., Ali, M. and Rabee, B.H. (2012) American Journal of Scientific Research, 69, 5-9.

[23] Zulfequar, M. and Kumar, A. (1989) Journal of the Electrochemical Society, 136, 1099-1102. https://doi.org/10.1149/1.2096792

[24] Farid, A.M., Atyiaand, H.E. and Hegab, N.A. (2005) Vacuum, 80, 284-294. https://doi.org/10.1016/j.vacuum.2005.05.003

[25] Ray, D.K., Himanshu, A.K. and Sinha, T.P. (2005) Indian Journal of Pure \& Applied Physics, 43, 787-793.

[26] Turky, G., Shaaban, S.S. and Schoenhals, A. (2009) Journal of Applied Polymer Science, 113, 2477-2484. https://doi.org/10.1002/app.30046

[27] Choudhary, S. and Sengwa, R.J. (2018) Current Applied Physics, 18, 1041-1058. 
https://doi.org/10.1016/j.cap.2018.05.023

[28] Langar, A., Sdiri, N., Elhouichet, H. and Ferid, M. (2017) Results in Physics, 7, 1022-1029. https://doi.org/10.1016/j.rinp.2017.02.028

[29] Mahapatra, T., Halder, S., Bhuyan, S. and Choudhary, R.N.P. (2018) Journal of Electronic Materials, 11, 6663-6670. https://doi.org/10.1007/s11664-018-6583-0 